\title{
PROPOSITION ANALYSIS OF FIXED BROADBAND SERVICES BASED ON PRODUCT SEGMENTATION AND PURCHASING POWER OF URBAN SOCIETY
}

\author{
Triyono Budi Santoso \\ Industrial Engineering Department, Faculty of Engineering, Bina Nusantara University \\ Jln. K.H. Syahdan No 9, Palmerah, Jakarta Barat, 11480 \\ triyono.budi@binus.ac.id
}

\begin{abstract}
Tight competition in the broadband industry has forced the provider to have a good product propotition and strategy in the market, including market segmentation and type of services delivered based on customer's expextation and intention to buy. This research aims to make a product proposition based on two major criteries in fixed broadband service, which are speed and price of the product, by looking into the competition in existing market (competitor's product). As many players in Indonesia have created very tight situation, the will be launched product should have an attractive matter or differentiation in order to compete and get a "buy in" of the customer. In the research, some analysis was conducted across all the propositions by spreading questionnaires to respondents in urban area especially in Jakarta and Bandung, thus the provider can create product with an appropriate specifications to answer the needs of customers on their affordable price to buy. Some close-ended questions in the questionairres were scaled and performed by basic statistical approach methods. The result shows that product with affordable price is still become the choice of respondents in each segment (low, medium and high income). Price list per speed which is fitted to any segments is also suggested in this research. The result of the research can also be used to develop the product as a differentiation to be the choices and preferencesof customers.
\end{abstract}

Keywords: fixed broadband, product proposition and pricing, marketing product management

\section{INTRODUCTION}

Based on the recommendation I.113 of the International Telecommunications Union (ITU), broadband is a technology that provides a transmission capacity that is faster than primary rate ISDN (1:5 or 2 Mbps). Broadband is identified as a technology with a set of services that is able to provide better quality when compared to traditional analog or dial-up technology (Polykalas \& Vlachos, 2006).

Fixed Broadband is a broadband service using cable technology (wirelined), which provides information and communication lines from the Central Office to users of the service. With such characteristics, fixed broadband ensures better quality than mobile broadband services that use wireless technology. Between fixed and mobile broadband, both support a very high speed communications, especially for internet data services. However, due to fixed broadband infrastructure has to be set up until the end of the customer, the investment for fixed broadband infrastructure is higher than the mobile, ranging from setting up a network backbone, last mile, as well as its back office system. Although it is comparable to the quality of service offered, the provider must make sure to go jump into the fixed broadband business. Not many providers are confident of this business opportunity. Therefore, the lean cost structure and the correct implementation strategy are required, and must be analyzed in a mature business plan, starting from a market research to capture the opportunities and needs (demand) from the public, especially in making a product proposition 
accordingly so that the provider can be right to invest to get the equilibrium as analysed by Rhee and Rhee (2009).

Fixed broadband penetration is still low in Indonesia, and it has prompted many operators vying to enter in this business. As a developing country, Indonesia needs to learn from the developed countries that have had a fixed broadband network infrastructure. Research showed that in a developed country like the United Kingdom, even required an understanding of consumer behavior when using the broadband service. Dwivedi, Lal and Williams (2008) described a number of drivers and barriers for an equitable adoption in broadband usage of a modern society. Inaccuracy in determining these factors will lead to the penetration of broadband and its implications will not be optimal.

The previous research of Lee and Brown (2008) used methodology of regression analysis and one-way ANOVA in exploring the factors that influence the use of broadband globally by examining factors such as: competition platform, ICT use, content, broadband speeds, income, population density, education, price, and local loop unbundling (LLU).

Although most of Indonesia's population covered by mobile communication, the quality of its broadband has not been evenly distributed. That's why, the presence of fixed broadband is expected to fill the gap in mobile broadband in terms of stability of quality. Both mobile and fixed broadband support the creation of a digital community that has been endorsed by the government. To achieve that, the role of the regulator which is the government is needed to sharpen the policy, strategy, and the utilisation of broadband networks (Sawyer, Allen, \& Heejin, 2003), especially when the policy is applied to the socio-economic structures of different communities (Polykalas \& Vlachos, 2006). It also calls for integrated innovation strategy for ICT systems (Information Communication and Technology) in Indonesia.

This research aims to make a product proposition based on two major criterias in fixed broadband service, which are speed and price of the product, by looking into the competition in existing market (competitor's product). As we know, there are many products and players in Indonesia such as indihome by Telkom, My Republic, Biznet, First Media, etc. In this tight situation, the expected launched product should have an interesting element or differentiation in order to compete and get a "buy in" of the customer. Through this research analysis and discussions, hopefully it can become a best practice approach in a real industry, i.e. telecommunication that can provide benefit to the providers and users in regards of the product determination to support this digital lifestyle era within a tight competition. Providers can create and determine a qualified competitive products, which are fit to the users' or market's demand.

\section{METHODS}

Method of factor selection used in this study was the conjoint analysis approach for products variable developed viewed from the aspect of bandwidth speed and price (representing the characteristic aspects of the customer in choosing a broadband product). Data was obtained by distributing questionnaires to a number of respondents in urban areas (in this case Jakarta and Bandung), by observing the different levels of people's income from low, medium and high categories. The scales analysis of close-ended questions shared was performed by a basic statistical approach, to get their willingness or intention to pay to the offered price per speed. Lee, Brown, and Lee (2011) stated that the significance of some demographic variables, such as income and education, imply that higher levels of income and education, as well as better economic climate are driving the broadband diffusion in countries, especially under their research on OECD (Organization for Economic Cooperation and Development). 
To ensure the validity of the survey, respondents selected are those who have authority in deciding/determining the willingness to buy/intention to pay or choose the product, as one of the parameters to be measured. These variables were chosen as part of integrated service quality as mentioned in Widaningrum and Santoso (2014), which was still a dominant factor for customer in adopting broadband service in their lifestyle especially in urban society.

The results were obtained as a product recommendations based on the speed bandwidth and price, and the selected cities that represent the digital lifestyle. The expected final results of this paper is the proposition of products in accordance with market conditions which is represented by those urban population, and the affordable price in accordance with the value created by the customers of every income level. Furthermore, this analysis can reflect the profit or revenue when the product will be released into the market, as revenue is a major parameter in a business.

\section{RESULTS AND DISCUSSIONS}

Questionnaires were submitted to the amount of respondents in the two largest cities in Indonesia, Jakarta and Bandung, as well as to some areas nearby, which has criteria for Low, Medium and High income levels. The products broadband internets are divided into four speed level: $5 \mathrm{Mbps}$, $15 \mathrm{Mbps}, 50 \mathrm{Mbps}$, and $100 \mathrm{Mbps}$. These speed levels represent the most offering products in both two cities by other providers.

Strategies as follower need to be developed as in the cities, the proposal is not the first entrance in market after years ago, some big and local players were there. Deep analysis and business calculation were made as a go to market periscope to broader opportunities across the field, since this type of business is still promising in Indonesia. Next, a product roadmap has to be arranged to assure the product life cycle development and management after it is launched to the market. Table 1 and Table 2 show the results of a survey to determine the respondents who are willing to pay the price of each product, as shown in the diagram below.

\begin{tabular}{c|c|c|c|c|c|}
\multicolumn{2}{c|}{ Low income } & \multicolumn{2}{c}{ Medium income } & \multicolumn{3}{c}{ High income } \\
\hline 5 mbps & 15 mbps & 15 mbps & 50 mbps & 50 mbps & 100 mbps \\
\hline & & & & & \\
\hline
\end{tabular}

Figure 1 Number of Respondents Who are Willing to Pay per Product Offered (For Jakarta and surrounding areas (total 1869 respondents) and prices in IDR) 
From the mapping of the willingness to pay of the respondents, compared to the number of broadband Internet products, there are variations in the distribution of any existing segments. In the low-income segment, in both cities surveyed, the data shows that the trend (the majority of respondents) expect the lowest tariff for categories of products offered. In the segmentation of respondents with middle income, the percentage of the price range in quartir 1 (the two lowest tariff are $250 \mathrm{~K}$ and $300 \mathrm{~K}$ for $15 \mathrm{Mbps}$, as well as $450 \mathrm{~K}$ and $500 \mathrm{~K}$ for $50 \mathrm{Mbps}$ ), for high income level, $50 \mathrm{Mbps}$ is in the range of $600 \mathrm{Ks}$ and $100 \mathrm{Mbps}$ is the range of $600-700 \mathrm{~K}$ (both for Jakarta and Bandung). By this mapping, it can also be concluded that for Bandung and its surrounding areas, the tendency to make the product proposition price which is above $900 \mathrm{~K}$ (as in the Jakarta area), is very small.
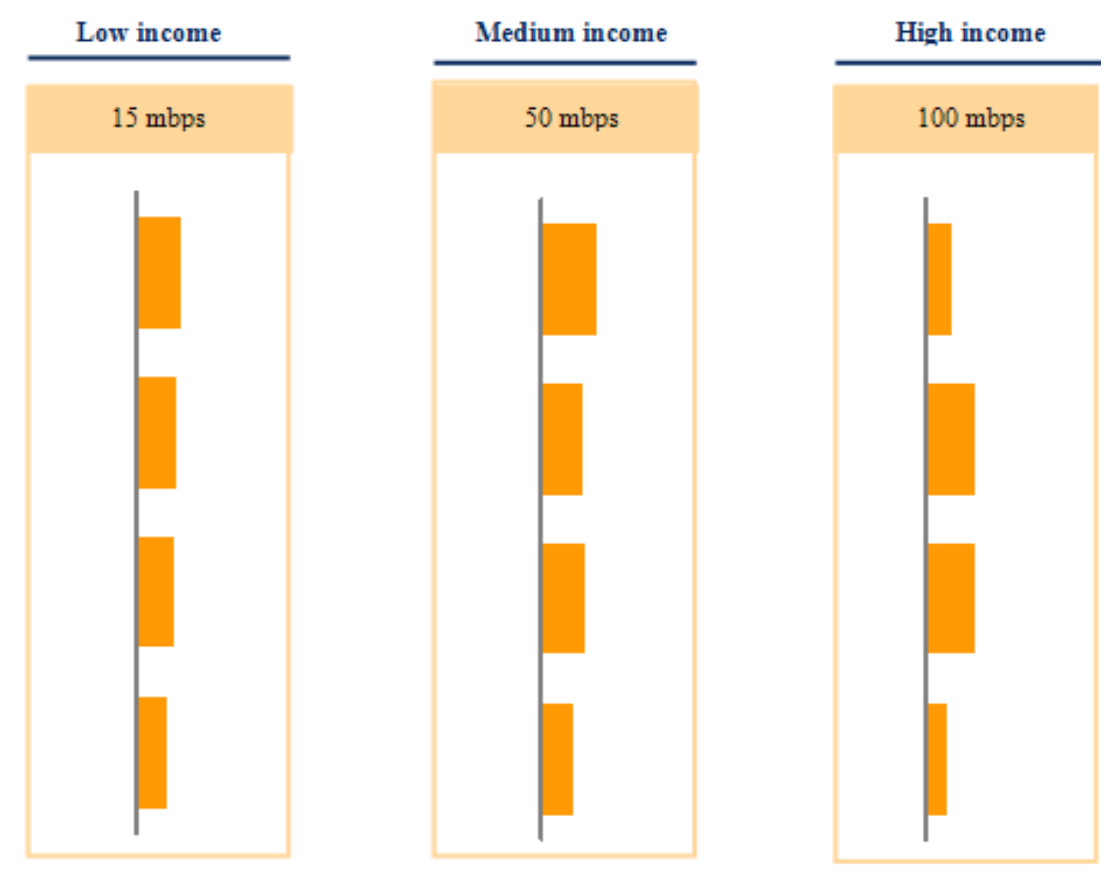

Figure 2 Number of Respondents who are Willing to Pay for Products Offered (For Bandung and surrounding areas (total 398 respondents) and prices in IDR)

Looking at the results, broadband internet product propositions in both cities shows the three variations of segment levels. However, the likelihood of those customers in wanting the cheapest price apparently occurs at all levels of price and speed.

Understanding the basic principle that customer is the king, and adjusting to the purchasing power of people in the cities based on the results of the survey and considering the feasibility aspects of the business, it needs a combination product (with variable speed) at a suitable and recommended pricing, before launching into the market. The recommended price is also considering the best value for money of it (consistent value for money).

Table of recommendations based on the calculation is shown in Table 3 and Table 4. The author also categorizes variants of the products offered, which has a catchy price based on price competition mapping on the market. 


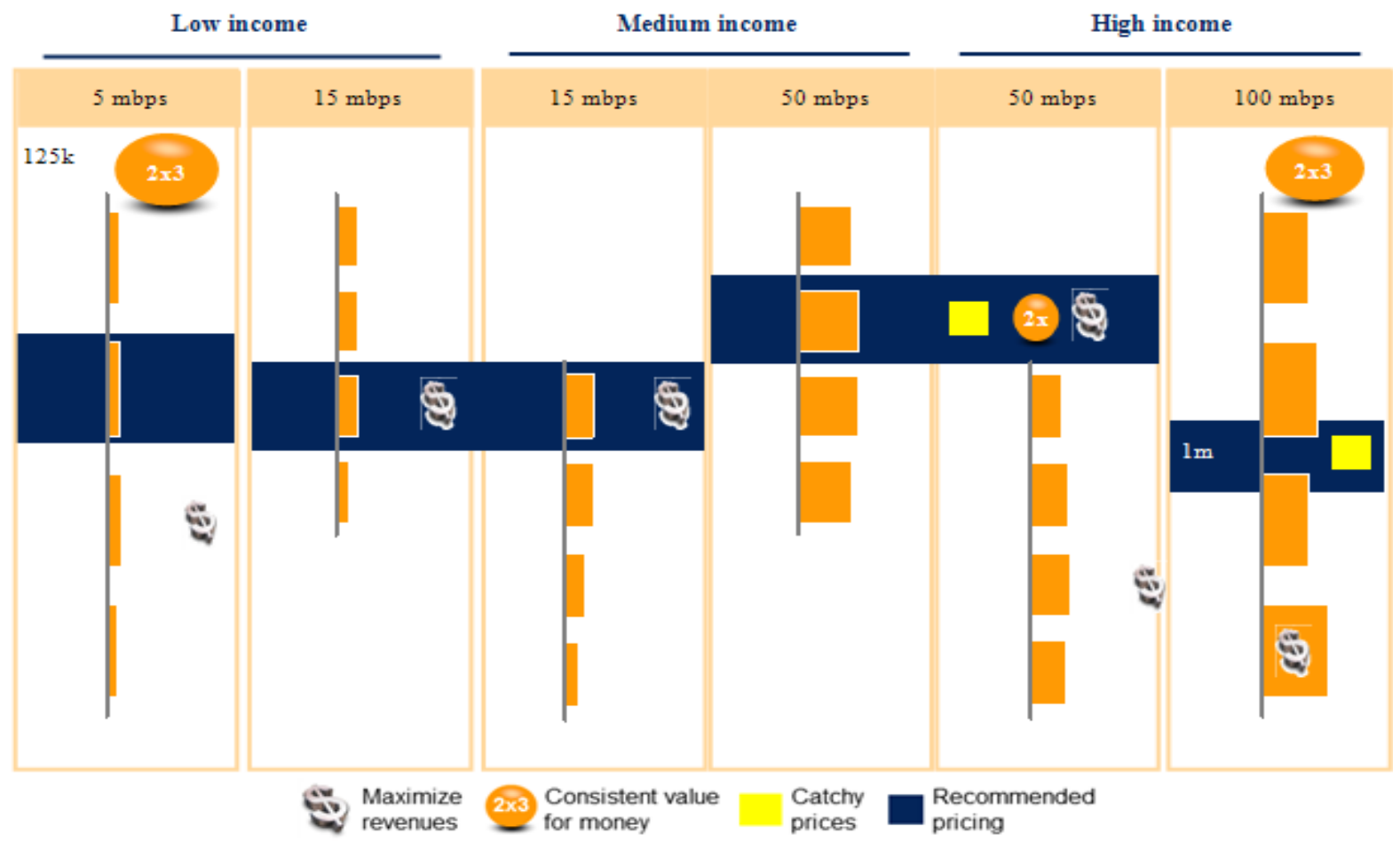

Figure 3 Recommendations per Product in Each Segment on Jakarta Area

As captured from the table, there are many situations in each product and each segment of Jakarta society. We can reflect the maximum revenue on IDR 200K at $5 \mathrm{Mbps}$, IDR 250K at $15 \mathrm{Mbps}$ both on low income level. While on medium income level, it looks like IDR 500K is offering a good position in terms of revenue, value consistency, and catchy as well. The proposal also proposes an "interpolation" price at high income level at IDR 1M as a catchy one, instead of IDR 1.3M as the highest revenue generator one.

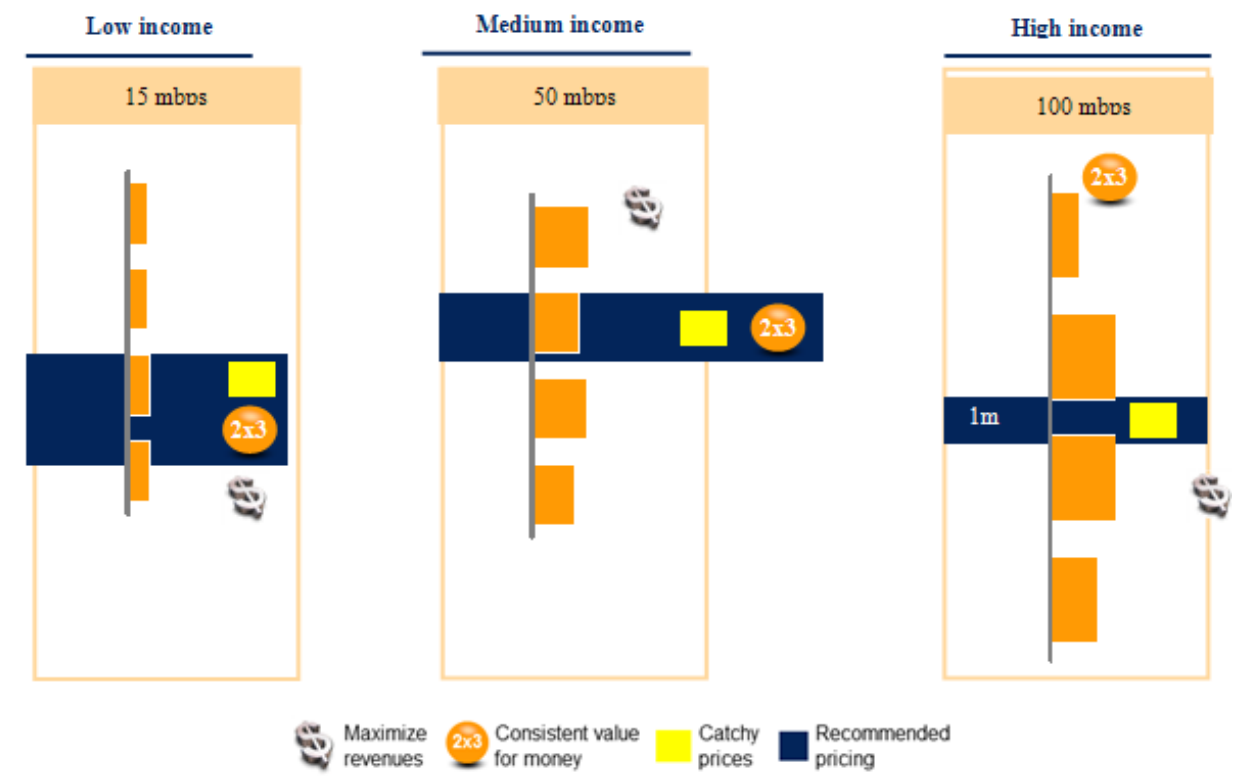

Figure 4 Recommendations per Product in Each Segment on Bandung Area 
Not much different with Jakarta, the society of Bandung also shows a short conclusion on price IDR 250K in low income for $15 \mathrm{Mbps}$, or IDR 500K in medium income for $50 \mathrm{Mbps}$, and IDR $1 \mathrm{M}$ in high income for $100 \mathrm{Mbps}$. This results lead to such confidence level to follow up in the phase of market execution. These pricing models and strategies can also be applied in other cities, including when we want to apply the price scheme for all, but also want to be flexible and applied by demography according to purchasing power and the existing competition mapping in each area.

Currently, some broadband service providers using FTTH technology/Fiber To The Home, and GPON is a lot, so that in the calculation of the business and the strategy still have to refer to the business plan, without ignoring the quality of service. Those above mentioned situations might bring us to a very dynamic analysis years ahead, especially in the implementation of the recommendation, also as we anticipate the competitor's movement and strategy whenever this proposition is launced.

\section{CONCLUSIONS}

This study discusses an aspect of marketing management from the aspects of product development which is in marketing management known as $5 \mathrm{P}$ (Product, Place, Promotion, Price, Profit) and 3C (Company, Customer, Competitor). The research data is taken in two major cities in Indonesia, indicating that the affordable product ("Freemium") is a product that is likely selected by the respondents. It requires a series of efforts and strategies that support the marketing and development so that whenever the product will be launched to the market, it is in great demand and chosen by customers. Because at the end, starting from planning and business analysis to the execution, the final result is still have to be a product that is qualified, and meet as much as possible of the customer expectations, which is based on this study, it is a product that has a high value but remains affordable in terms of its price.

Further research may have a sensitive analysis and monitor tracking along the time as this recommendation is executed, to understand and determine the effectiveness of the program/project and to get feedback from customers about the quality that is delivered. Also, further research can take into account the generated revenue, so that huge investments which are spent can be accounted for. Until now, the investment cost for 1 (one) unit of fixed broadband connections is still high at around IDR $2000 \mathrm{~K}$, out of the cost of the backbone transmission and international capacity leasing. At the stage of research in the next implementation phase, it can also be combined with product marketing strategy that is appropriate with the real condition of the future, whether done in ATL (Above the Line) and BTL (Below the Line) so that the product can be better known in the market.

\section{REFERENCES}

Dwivedi, Y. K., Lal, B. \& Williams, M. D. (2008). Managing consumer adoption of broadband: examining drivers and barriers. Industrial Management \& Data Systems, 109(3), 357-369.

Lee, S., \& Brown, J. S. (2008). Examining broadband adoption factors: an empirical analysis between countries. Info, 10(1), 25-39.

Lee, S., Brown, J. S., \& Lee, S. (2011). A cross-country analysis of fixed broadband deployment: examination of adoption factors and network effect. Journalism and Mass Communication Quarterly, 88(3), 580 - 596. 
Polykalas, S. E., \& Vlachos, K. G. (2006). Broadband penetration and broadband competition: evidence and analysis in the EU market. Info, 8(6), 15-30.

Rhee, H., \& Rhee, S. (2009). An analysis of equilibrium relationship between price elasticity and expenditure level: a case study of Korean mobile market data. Journal of Economic Development, 34(2), $69-83$.

Sawyer, S., Allen, J. P., \& Heejin, L. (2003). Broadband and mobile opportunities: a socio-technical perspective. Journal of Information Technology, 18(2), 121-36.

Widaningrum, D. L., \& Santoso, T. B. (2014). Determining Mobile Broadband Adoption Factors to Support Digital Lifestyle Activity: A Pilot Test Among Jakarta Broadband Consumer. Australian Journal of Basic and Applied Sciences, 9(7), 251-254. 